\title{
Ayacucho: el uso de las tecnologías visuales como evocadoras de memoria y sentido de pertenencia $^{1}$
}

\section{Rocío E. Trinidad}

Pontificia Universidad Católica del Perú

trini.trinita@gmail.com

\section{RESUMEN}

El artículo aborda las formas de utilización de las tecnologías visuales, la fotografía y el video, para promover la ciudad de Ayacucho como destino turístico, como constructor de identidad, evocador de memoria y sentido de pertenencia a la ciudad. Presta atención al uso que para ello se hace de la arquitectura como tecnología de la imagen, a través de la cual se busca producir simulacros temporales y estructuras de sentimiento relativas al período colonial. Argumenta que la identificación y el uso de la estética colonial o no en las edificaciones de Ayacucho sirve para para establecer clasificaciones sociales, distinciones y exclusiones entre quienes se consideran «huamanguinos» y los «nuevos huamanguinos». El artículo está dividido en dos partes. En la primera aborda los videos que promueven Ayacucho como destino turístico, y en la segunda, el uso de las fotografias en exposiciones y redes sociales.

Palabras clave: Huamanga, Ayacucho, arquitectura, memoria, fotografía, video.

\footnotetext{
1 Este artículo es una versión extendida y actualizada del capítulo 5 de la tesis doctoral $(R e)$ presentando Ayacucho: debates en torno al cambio, el turismo y la imagen arquitectónica en tres momentos históricos, presentada para optar el grado de doctora en Antropología. Lima: PUCP.
} 


\section{Ayacucho: The use of visual technologies as memory evocative and sense of belonging}

ABSTRACT

The article deals with the ways of using visual technologies, photography and video, to promote the city of Ayacucho as a tourist destination, an identity builder, reminiscent of memory and a sense of belonging to the city. Pay attention to the use, made for this purpose, of architecture as an image technology through which it seeks to produce temporary simulations and sentiment structures related to the colonial period. Argues that the identification and use of colonial aesthetics or not in the buildings of Ayacucho serves to establish social classifications, distinctions and exclusions among those who identify themselves as «huamanguinos» and «new huamanguinos». The article is divided into two parts. The first deals with the videos that promote Ayacucho as a tourist destination and the second with the use of photographs in exhibitions and social networks.

Keywords: Huamanga, Ayacucho, architecture, memory, photography, video. 


\section{INTRODUCCIÓN}

Soy un ojo. Un ojo mecánico. Yo, la máquina, os muestro un mundo del único modo que puedo verlo. Me libero hoy y para siempre de la inmovilidad humana. Estoy en constante movimiento. Me aproximo a los objetos y me alejo de ellos. Repto bajo ellos. Me mantengo a la altura de la boca de un caballo que corre, caigo y me levanto con los cuerpos que caen y se levantan. Esta soy yo, la máquina, que maniobra con movimientos caóticos, que registra un movimiento tras otro en las combinaciones más complejas. Dziga Vertov, 1923, citado por Berger, Blomberg, Fox, Dibb y Hollis, 1974, p. 24

El Manifiesto de Dziga Vertov hace referencia a las capacidades que brinda un nuevo recurso: la cámara de cine. Esta tecnología innovó el registro y la visualización de las imágenes. El ojo mecánico llegó más allá de donde llegaba el ojo humano, el que por su naturaleza no puede estar en todas partes al mismo tiempo y solo capta una cosa en un solo momento (Berger et al., 1974, p. 10). La invención de la cámara de cine permitió el desplazamiento, acercamiento y circulación de las imágenes a través del globo, para así ver gente, lugares y cosas que no estaban a nuestro alcance. Benjamin, ya en 1936, reflexionaba sobre cómo la cámara y su capacidad para reproducir imágenes no solo modificaban la forma en que estas se veían (estructura) sino cómo las veíamos (sensorium) (Benjamin, 2011, p. 12).

Ayacucho, como objeto que se reproduce mediante imágenes, sale a nuestro encuentro desde donde estemos. La ciudad es construida, reproducida, distribuida y consumida por medio de películas, fotografías, souvenirs, tarjetas postales y otros, llegando así a ser conocida por gente que nunca estuvo ahí y quizá tampoco llegue a estarlo. La representación de la ciudad también se refleja en interesantes audiovisuales que combinan imágenes fijas en secuencias animadas con música y voz en off, que están alojados en el sitio web YouTube y también en la red 
social Facebook. En este artículo presentaré las formas de utilización de las tecnologías visuales, la fotografía y el video, para promover la ciudad de Ayacucho como destino turístico y como constructor de identidad, evocador de memoria y sentido de pertenencia a ella. Prestaré atención al uso que para ello se hace de la arquitectura como tecnología de la imagen, a través de la cual se busca producir simulacros temporales y estructuras de sentimiento relativas al período colonial.

\section{LOS VIDEOS: PROMOVIENDO AYACUCHO COMO DESTINO TURÍSTICO}

Lo visual es fundamental en el consumo turístico (Urry, 2004, p. 89). El canal YouTube alberga, entre otros, videos turísticos que destacan por su intención de publicitar la ciudad mediante el uso de imágenes típicas. Por imágenes típicas entiendo las referencias iconográficas sobre escenas costumbristas asociadas a un lugar y tiempo determinado. En ellas se establece visualmente la asociación causal entre espacio, cultura e identidad, vinculación solo sostenible en la ficción del video, pues en el cotidiano de Ayacucho todo es más gris, dislocado e híbrido.

A través de un conjunto de imágenes de la ciudad, cuidadosamente escogidas, tomadas desde sus mejores ángulos, se fija su identidad y se le aprecia como imperecedera, lo que equivale a decir que el tiempo se congela en el lugar. Tal es el caso del video titulado Ciudad Señorial de Huamanga-Ayacucho. Este inicia su recorrido con una descripción de aproximadamente 2'12" de las características del paisaje urbano. En un fragmento, la voz en off dice:

La apacible ciudad de Huamanga es una ciudad bendecida porque posee un sinnúmero de atractivos de arquitectura, arte colonial, culturas vivas, historia y naturaleza, son sus encantos que te cautivarán si llegas a visitarlo. Huamanga radiante, con un clima bondadoso y sol todo el año, acoge a más de 150000 habitantes. Esta ciudad se ha convertido en una próspera localidad con su gente pujante y amable con el visitante, lo convierte en la tierra más acogedora del Perú. La naturaleza le ha concedido los paisajes más increíbles, que se convierten en paraísos ideales para visitar los fines de semana. Su gente mestiza se ha encargado de construir más de 33 hermosos templos que acogen a los cristianos y que son visitados por miles de turistas durante todo el año. Sus hermosas casonas coloniales que sirvieron como viviendas a los conquistadores han sido construidas a base de piedras labradas artísticamente, sus callejuelas te invitan a retroceder en el tiempo, las viviendas son tejadas de arcilla roja...2.

2 Video turístico Ciudad Señorial de Huamanga-Ayacucho (10’21"), s/f. http://www.youtube. $\mathrm{com} /$ watch? $\mathrm{v}=\mathrm{uO} 1 \mathrm{M} 8 \mathrm{RrUoA} 4 \&$ feature=related (acceso: 6 de enero de 2018). 
Si leyéramos el texto presentado sin visualizar el video, podríamos construir la ciudad de Ayacucho en nuestra imaginación de forma más libre, aunque pautada por nuestros conocimientos previos sobre ella. Sin embargo, si visualizáramos el video, la experiencia sería diferente. En ese caso se presentaría una tensión entre nuestra «acción imaginante», capacidad de «deformar» y «cambiar» las imágenes (Bachelard 1958, p. 9), y la poética y retórica de las imágenes, que pretende convencer y fijar que Ayacucho es tal cual el video muestra y no de otra forma. En el video en análisis, se busca orientar la construcción de la ciudad de nuestra imaginación por el movimiento de la cámara, el guion, la voz en off y la selección de las fotos con las que el productor ha escogido componer visualmente el mensaje turístico. Con todo ello, el realizador del video busca conducir al espectador a sacar sus propias «conclusiones». En otras palabras, la imagen «presta su autoridad al realizador del film» para persuadir al espectador (Berger et al., 1974, p. 15).

Es de resaltar la importancia del control y manipulación de la imagen arquitectónica que circula en las fotos y en los films para construir la ficción de las apariencias. El productor audiovisual tiene que compensar a su audiencia, mediante imágenes, de su «imposibilidad de la experiencia directa» y convencerla de la autenticidad de la Huamanga tradicional, mostrando selectivamente sus atractivos arquitectónicos, tal como hace el video, «los paisajes más increíbles», «33 hermosos templos», «hermosas casonas coloniales», viviendas «tejadas de arcilla roja». Y no paisajes ruinosos, templos descuidados, casonas estéticamente indefinidas ni viviendas con techos de calamina. Para lograrlo, el «origen tecnológico de la imagen» contribuye a brindar «garantía de objetividad» a las audiencias del contenido del documento visual (Fontcuberta, 1997, p. 120). Ello, aunado a que supuestamente lo visual legitima la existencia de lo real, cumple con el aforismo veo, entonces creo. Pero la ciudad de Huamanga es solo una representación. Si, como dice Benjamin, «el aura está ligada al hit et nunc, no hay reproducción del aura» (2011, p. 27), entonces, el aquí y ahora pasó, y tan solo se repetirá como «el encanto discreto de los simulacros de segundo orden» (Baudrillard 1978, p. 5), lo que equivale a decir meras reproducciones arquitectónicas.

Ello me remite a la película Bienvenido Mister Marshall (1953), de Luis García Berlanga, ambientada en la España posterior a la Segunda Guerra Mundial en el contexto de la difusión del Plan de Recuperación de Europa —más conocido como Plan Marshall_, impulsado por el gobierno de los Estados Unidos de Norteamérica. Trata de la expectativa generada por «los americanos» representantes del Plan en Villar del Río, un pueblo de Galicia no muy conocido. 
Las autoridades locales, motivadas a su vez por las autoridades provinciales, se preparan para recibirlos con honores y, de paso, obtener beneficios. Para ello, en medio del decaimiento económico propio de la posguerra, se les ocurre «construir» un escenario de ciudad y «construirse», ataviándose con vistosos trajes. Toman como modelo Andalucía, por ser una región conocida, asumiendo que «los americanos», por su desconocimiento, poco o nada percibirán las diferencias. A lo largo de la película, se aprecia cómo los pobladores de Villar del Río construyen una escenografía de ciudad. Especial atención ponen en la producción de las fachadas impolutas, que invisibilizan todo lo que no es compatible con la estética que quieren presentar. Lo mismo se ve en el caso de los vestidos andaluces elegidos, que con su colorido buscan ocultar su deslucido vestir cotidiano. Gran producción, grandes actores y escenario magnífico montado en un lugar al cual «los americanos» no arriban, sino que pasan raudos y veloces en sus autos, dejando tras de sí solo el polvo como símbolo de su indiferencia. Al día siguiente, la ciudad se desmonta, los vestidos se devuelven, las luces se apagan.

¿Cuáles serían las similitudes entre la ficción en Villar del Río y lo que ocurre en Ayacucho? Una primera, que ambos están a la espera de un ingreso foráneo que los beneficie económicamente. Mientras en Villar del Río esperan a «los americanos» y el Plan Marshall, en Ayacucho la motivación es la llegada de los turistas. Una segunda es la atención que prestan a la estética para atraer a los foráneos, lo que se expresa en la construcción de la ciudad. Ello se reduce a una representación de la identidad primordial en la cual la arquitectura, como escenografía, es fundamental para crear el simulacro esperado. Y, en tercer lugar, la decepción frente a la expectativa generada, aunque en este punto existe variantes. Mientras en Villar del Río se desmonta el simulacro ante la indiferencia de «los americanos», en Ayacucho no se pierde la esperanza de ser un lugar turístico ${ }^{3}$, por tanto, los simulacros se refuerzan mediante controles normativos, censuras sociales e invención de tradiciones tales como Morada del Alma, el nuevo significado del nombre de Ayacucho que se pretende instaurar en el contexto del postconflicto. La nueva interpretación pretende desmontar el estereotipo del Ayacucho de la violencia y su asociación como Rincón de los Muertos y reasociarlo con la tranquilidad, la paz. A partir de 1993, con la publicación del artículo

Ayacucho aún no logra competir con Lima, Cusco, Puno y Arequipa, los cuales ocupan los primeros lugares de los destinos turísticos en el país. INEI. Compendio estadístico. Turismo. Ciudades más visitadas en el Perú, por país de procedencia (2014). https://www.inei.gob. pe/media/MenuRecursivo/publicaciones_digitales/Est/Lib1253/cap20/cap20034.xls (acceso: 20/08/16). 
de Juan Tincopa Calle Ayacucho, Morada del Alma, se empieza a difundir a la ciudad con ese nombre en el entendido de que es la interpretación fidedigna de la traducción castellana del vocablo quechua Ayacucho. No obstante, esta nueva interpretación también tuvo detractores (Cavero, 2005), para quienes se trataría de una estrategia de marketing de PromPerú4.

Al respecto, es ilustrativo el video Ayacucho mágico ${ }^{5}$, el cual cuenta la historia de Luis, quien invita a Verónica, la joven que le gusta, a pasar unos días en Ayacucho. La historia cuenta que él escoge el lugar por ser un escenario tradicional, histórico, hermoso y también por ser propicio para el romance. A lo largo del video, el joven imagina varias formas para evidenciar sus intenciones a su amada, pero se pierde en el ensueño que le evoca el lugar. Aun estando Verónica presente en los episodios de su imaginación, él es el gran protagonista. Así, en la Pampa de la Quinua, Luis se imagina como un soldado patriota, y en las ruinas de Vilcashuamán formando parte de la realeza incaica. Ella es más pragmática: vive cada momento cautivada con el magnífico escenario donde se encuentra. Lo disfruta al máximo, degustando los platos típicos, escuchando música, bailando e inmortalizando cada momento con su cámara fotográfica, sin darse por enterada de las intenciones de su compañero de aventuras. Dejándose llevar por la experiencia sensorial que Ayacucho les provoca, la atmósfera romántica se hace presente progresivamente hasta llegar a la escena en la que se le ve a ella disfrutando con él de un baño en una hermosa laguna. El marco preciso para el romance: sus ojos se encuentran y, sin decir más, se dan un beso.

En suma, Ayacucho, tal como reza el título del video, «es mágico» ${ }^{6}$, el lugar donde todos tus sueños pueden hacerse realidad. Además de su patrimonio histórico y cultural, la narrativa visual lo presenta como un lugar propicio para el

4 Cabe resaltar que la primera publicación de esta nueva interpretación del nombre de la ciudad se da en 1993, el mismo año que se crea la Comisión de Promoción del Perú PromPerú (un año después de la captura de Abimael Guzmán, 12 de setiembre de 1992), y el mismo año en que Alberto Fujimori llega por primera vez a Ayacucho. Arribó el Jueves Santo de 1993 y permaneció hasta Domingo de Resurrección. Durante su estadía participó en las festividades religiosas y con su presencia buscó afirmar el retorno de la normalidad a la ciudad, exhibirse como el restaurador del orden perdido y como el artífice de la llamada pacificación (Reporte Especial, DESCO N²1, abril de 1993 (p. 9).

5 Video documental Ayacucho mágico (30'), producido por el Dicetur-Ayacucho, s/f. http:// www.youtube.com/watch?v=V4eTmdW3chk (acceso: 9 de enero de 2018).

6 En una línea similar, el análisis del video Perú: el «Royal Tour» (Vich, 2007) afirma que la performance del presidente Toledo, quien es el anfitrión del viaje, está dirigida a producir un Perú que no existe, a «inventarlo» como un lugar «mágico» y «místico», por ser estos los elementos fundamentales que requiere el nuevo turismo internacional. 
placer, el romance y el disfrute. Ninguna referencia al pasado reciente: el conflicto es aquello de lo que no se habla, pues alude a muerte, que es justamente lo que se busca desterrar visualmente y desinstalar de la narrativa del marketing turístico. De ello se desprende que la motivación para el consumo no es solo materialista: la gente también busca «experimentar 'en la realidad' los dramas placenteros que ya han vivido en su imaginación» (Campbell, 1987, citado por Urry, 2004, p. 18). Esos «dramas placenteros» que no son experiencias individuales, sino que «están organizadas socialmente» a través de lo que se ofrece, entre otros, por los medios de comunicación (Urry, 2004, p. 86). Así, los lugares «a mirar», para hacer turismo se eligen porque "anticipan intensos placeres», «dicha anticipación se construye y sostiene mediante diversas prácticas no turísticas, tales como películas, TV, literatura, revistas, discos y videos, con los que se construye y refuerza dicha mirada» (Urry, 2004, p. 7). El video, producido por Dicetur-Ayacucho, cuyo guion está escrito por uno de los más conocidos cineastas ayacuchanos -el recientemente fallecido Palito Ortega Matute, quien también lo dirigió- combina el melodrama y la información turística para invitar al espectador a identificarse con la historia, a la par que puede construir su propia historia si viaja a Ayacucho. El video está en la línea del marketing de la experiencia y en consonancia con el auge del capitalismo cultural. La economía de la experiencia que ha sucedido al capitalismo industrial, propio del mercado tradicional (Riviere, 2000), que como señala Rifkin tiende a transformar los recursos culturales en experiencias personales (Rifkin, 2000) 7 .

Lo sucedido en Ayacucho no es excepcional. La imagen es fundamental para «instaurar una identidad en el mercado» (Harvey 2004, p. 319). Ante tanta oferta de ciudades, es necesario crear una diferencia con el fin de hacerse atractivos para el capital, para lo cual se conserva la tradición, se la reconstruye y, si no existe, esta puede ser producida como un simulacro a través del uso de la arquitectura. Los simulacros proliferan en el contexto del capitalismo tardío, «encubriendo casi perfectamente cualquier huella del origen», es decir, ocultando «los procesos de trabajo que los produjeron, o de las relaciones sociales implicadas en su producción» (Harvey 2004, p. 332). Los simulacros arquitectónicos diseñan ciudades para las cámaras y para satisfacer los deseos de los turistas, es así como la «ciudad se va transformando, produciendo, iluminando, rehabilitando,

Vich, en su artículo Perú: el «Royal Tour», también llega a esa conclusión: citando a Zizek, postula que en la nueva etapa del capitalismo la producción se encuentra desmaterializada y que el «rasgo definitorio del capitalismo posmoderno es la mercantilización directa de la experiencia misma» (Vich, 2000). 
maquillando, disfrazando, va adoptando símbolos universales de consumo para sobrevivir en el mundo del espectáculo y el entretenimiento» (Lins Correa, 2007, p. 52). La imagen tiene un papel fundamental en la construcción de simulacros, es por ello que, en el capitalismo de consumo, la imagen puede ser entendida como una mercancía (Harvey, 2004, p. 318). Sin embargo, no todo obedece a fines turísticos. En un artículo previo (Trinidad, 2006) sostuve que el turismo no era la única explicación del interés de la ciudad de Ayacucho para mantener la arquitectura colonial y que era necesario ir más allá de la construcción de la ciudad como mercancía, apuntando a los deseos y fantasías de los locales que se enmascaran detrás de ese argumento. Si tomamos en cuenta que la arquitectura, además de ser una tecnología de la imagen, es un medio de comunicación y un símbolo de poder, es posible entender que, a través de su uso y las estéticas que se elijan para ataviar las edificaciones, se puedan establecer no solo distinciones sociales, sino clasificaciones de pertenencia y exclusión respecto de la ciudad.

Veamos el caso de las Normas para la ampliación, remodelación, refacción y puesta en valor de las edificaciones en el Centro Histórico de Ayacucho, elaboradas por la Municipalidad Provincial de Huamanga ${ }^{8}$. Se trata de unas cartillas elaboradas a colores y en papel couché en las que, a través de imágenes y palabras, se interpela, a través de un discurso pedagógico, no solo a compartir una determinada estética, sino a disciplinar el comportamiento ciudadano. La arquitectura y el urbanismo funcionan como herramientas de la gubernamentalidad, a través de las cuales se busca disciplinar el cuerpo de la ciudad y los cuerpos que en ella habitan (Trinidad, 2006, p. 11). Ello recuerda los «manuales de urbanidad», una práctica disciplinaria utilizada durante el siglo XIX y las primeras décadas del siglo XX para construir a los ciudadanos latinoamericanos. Los manuales de urbanidad reglamentaban el comportamiento «que debían asumir los habitantes de la ciudad» para ingresar al mundo civilizado y alcanzar la modernidad (Gonzales Stephan, 1994, pp. 110-111). El ingreso a la «modernidad» demandaba el cumplimiento del «recetario normativo», el cual servía para «distinguir a los miembros de la nueva clase urbana que empezaba a emerger en el siglo XX» (Castro-Gómez, 2000, p. 12). De ello se desprende que el manual de urbanidad del siglo XIX no solo reglamenta, sino que sirve para producir diferenciaciones. Haciendo un símil con las cartillas municipales ayacuchanas elaboradas en pleno siglo XXI, es

Un análisis detallado de las Normas para la ampliación, remodelación, refacción y puesta en valor de las edificaciones en el Centro Histórico de Ayacucho se puede encontrar en el capítulo 3: Arquitectura como estética y política de Trinidad (2013). 
posible afirmar que ellas, utilizando la materialidad de la arquitectura, avalando la estética colonial y rechazando las estéticas híbridas, establecen abiertamente una clasificación jerárquica entre ambas y al hacerlo, indirectamente, intentan restablecer la estructura de sentimiento colonial. Este sentimiento puede parecer etéreo, pero, como dice Williams, es «tan sólida y definida como lo sugiere el término estructura» (Williams, 2003, p. 57).

La clasificación jerárquica de las estéticas mencionadas líneas arriba no solo acredita la validez de lo colonial, legitimándolas como lo bello y representativo de Huamanga, sino que, además, sirve para distinguirse como huamanguino y distinguir, según sigan o no la estética colonial, a los llamados huamanguinos de quienes no lo son. Así, la huamanguinidad de la ciudad se construye en términos materiales por medio de la arquitectura y en términos subjetivos por el sentimiento ligado a la «cultura de un período» (Williams, 2003, p. 57) —en este caso el colonial-, en donde la ciudad de Huamanga era una de las más importantes. Podría argumentarse que también existe un sentimiento de orgullo ligado a la época republicana, fundamentalmente por el rol de Ayacucho en la gesta independentista. Ciertamente, pero cabe recordar que, si bien fue significativo, ese período también estuvo asociado a drásticos cambios y pérdidas que van desde el cambio de nombre de Huamanga a Ayacucho, la disminución de la población, el abandono en el que se sumió la región y el cierre de la Real Universidad de San Cristóbal de Huamanga ${ }^{9}$, todo lo cual conduce a mirar al período anterior.

\section{FOTOGRAFÍAS: HUAMANGUINOS Y HUAMANGUINIDAD}

«Suspiramos por los ayeres y los mañanas sin darnos cuenta de que... el hoy, amargo o dulce, inquieto o tranquilo, es el único día para nosotros. El sueño del tiempo es el traidor y todos nosotros somos cómplices de la traición a nosotros mismos» (citado por Lowenthal, 1998, p. 69).

Huamanga no es la capital de la región Ayacucho sino el nombre de la provincia en la que se ubica la capital, cuyo nombre es Ayacucho. Huamanga fue el nombre colonial de la ciudad, el que se cambió a Ayacucho en honor a la batalla

9 En 1825, después de lograda la independencia y con la intención de eliminar los rezagos coloniales en las instituciones y reapropiarlas para la reciente república, la universidad vio cambiado su nombre a Nacional y Pontificia Universidad de San Cristóbal de Huamanga. En 1886, el mariscal ayacuchano Andrés Avelino Cáceres la clausuró, debido a que los gastos originados por la guerra con Chile (1879) impedían seguir solventando el presupuesto de dicho centro de estudios (Trinidad, 2013, p. 45). 
que consolidó la independencia. Sin embargo, Huamanga es el nombre utilizado cotidianamente para nombrarla. En 1999, el discurso de orden pronunciado por Iván Ruiz Ayala, en ese entonces presidente del Club Departamental Ayacucho de la ciudad de Lima, con motivo de conmemorarse el $459^{\circ}$ aniversario de la fundación española de la ciudad de Huamanga, subrayó lo significativo de la persistencia de esa práctica de llamar Huamanga a Ayacucho, pese a los años transcurridos del cambio de nombre. Atendiendo, dice, a que «desde hace algunos años existe un sentimiento generalizado en la ciudad para recuperar el nombre histórico de la ciudad de un modo oficial», propone reivindicarlo, ya que la ciudad nació como tal el 25 de abril de 1540, fecha de la fundación española, y no el 9 de diciembre, que es la fecha de la batalla de Ayacucho. Es así que la reivindicación de Huamanga, dice, va más allá del reclamo por el nombre: implica la demanda del reconocimiento de su lugar en la historia.

Nadie desconoce la importancia que para su tiempo tuvo la batalla de Ayacucho en la historia del Estado peruano y entre el conjunto de países latinoamericanos, pero hoy creemos que quienes deciden el destino de un pueblo, de una ciudad, son sus propios actores, esto es, sus habitantes, sus hijos, nosotros, quienes hemos nacido en esa ciudad y en ese departamento. $\mathrm{Y}$ reivindicamos no solo un nombre: reivindicamos los siglos de historia que van anexos a él. La ciudad no nació el 9 de diciembre de 1824, sino que su historia se remonta al 29 de enero de 1539, día de su fundación, y al 25 de abril de 1540, fecha de su traslación al llano de Pucaray, donde ahora se asienta.

Ciertamente, «nominar es un ejercicio de poder» (Guarné Cabello, 2004, p. 50) y también de memoria, que se relaciona con el significado que tenía la ciudad en la colonia; por tanto, la demanda de reivindicar su pasado de gloria es altamente revelador si tomamos en cuenta que ella proviene de aquellos integrantes de la élite ayacuchana, representada en el Club Departamental Ayacucho, que además desde hace varios años radican en Lima. Implica una necesidad de reafirmar el origen distinguido de la ciudad en medio de lo gris de su composición presente. Ello se encuentra en relación con la huamanguinidad, ese sentimiento socialmente construido de apego, conexión y pertenencia hacia un espacio, en este caso Huamanga, el cual se forja mediante la apropiación de la memoria y la historia. La práctica de ese sentimiento promueve la identificación local a la vez que establece diferenciaciones, en términos étnicos y de clase, entre quienes la expresan o no. Los términos huamanguino y nuevo huamanguino son expresión de ello y surgen como formas de clasificación social. 
¿Qué es ser huamanguino? Huamanguino es un adjetivo que no alude precisamente a la localidad de nacimiento, sino que se usa para marcar una procedencia, un linaje asociado a las familias tradicionales. Tal como señala el antropólogo ayacuchano Álamo Ubilluz, quienes se consideran «huamanguinos» se remontan a la época colonial, aludiendo a su estirpe, a lo que fueron y a lo que tuvieron.

Los que se consideran «huamanguinos» se solazan siempre que hablan de la alcurnia de los personajes y ciudadanos notables de la época de la colonia hasta nuestros tiempos, ligados a las haciendas y los fundos. Pero a través de los recuerdos se tiene conciencia del cambio, que es claro y se expresa en la comparación de los tiempos anteriores con el presente. Por ello las personas mayores, al narrar la historia local, resaltan lo ido, lo ya clausurado, lo que no va a volver (Ubilluz, 2005, p. 68).

Pero ¿quiénes son los nuevos huamanguinos del Ayacucho del milenio? No son quienes descienden de las familias tradicionales - muchas de ellas están en Lima desde hace varias décadas - sino aquellos que ocuparon el lugar dejado por estas. Los que fueron considerados como «los otros» por los huamanguinos de su tiempo, por llegar a poblar la ciudad, por ejemplo, para estudiar o trabajar en la universidad durante la década de 1960. Ellos son, ahora, huamanguinos por ocupación y tiempo, tal como es el caso de Julio, a quien conocí durante mi trabajo de investigación en Ayacucho. Él, natural de Jauja, arribó a Ayacucho en 1959, con 21 años, para estudiar en la reabierta Universidad Nacional de San Cristóbal de Huamanga (UNSCH). La educación fue su medio de movilidad social, se hizo profesional y ocupó altos cargos académicos en la UNSCH, se casó con una mujer de Huamanga y tuvo hijos, todos huamanguinos y profesionales como él. Julio hizo de Huamanga su hogar y su presente, y de Jauja su lugar de nacimiento, al cual regresa solo el Día de los Muertos para visitar las tumbas de sus padres, su pasado.

Algunos de los nuevos huamanguinos del Ayacucho contemporáneo consideran a quienes arribaron con las migraciones del campo a la ciudad, para guarecerse de la violencia, como los otros. Se observa así una especie de transitividad en la construcción de la alteridad y de la identidad huamanguina. Los anteriores otros, al sentirse legítimos y naturales del lugar, otrean — si vale el término- a los recién llegados con profusión a partir de la década de 1980. Estos otros, quizá pasado el tiempo, adquirirán carta de ciudadanía y se convertirán en huamanguinos que reclamarán para sí su espacio, otreando a los que lleguen después.

Los que se definen como huamanguinos reclaman para sí la ciudad, la tradición y la tranquilidad de los tiempos idos, de los que algún día gozaron y que ya 
no regresarán más. Nuevos huamanguinos han poblado la ciudad y la han hecho cambiar. Nuevos rostros se observan: muestra de ello son los retratos de Baldomero Alejos, cuya obra abarca desde 1924 hasta 1976: un período de 52 años en los que de retratar a la élite ayacuchana, a los señores «visibles» de antaño, durante la década de 1960 y 1970 dio paso a las fotos carnet, capturando nuevos rostros, de gente más común y desconocida. Esto refleja una cierta democratización social y el declive de los rezagos coloniales basados en la portación de apellido y estatus, lo que delata el cambio de la composición social de la ciudad, tal como describe Carlos Iván Degregori en su análisis de la memoria visual del mencionado fotógrafo:

En las décadas de 1960 y 1970 el registro de Alejos se amplía, otros personajes y otras capas sociales logran acceso a la fábrica de imágenes que comienza a alejarse de los sueños para captar casi etnográficamente la realidad huamanguina en vísperas de su Apocalipsis. Otros rostros: otras mujeres, más audaces; otros varones, tal vez no tan seguros, tal vez algo más cansados; otras celebraciones y otras conmemoraciones. Hasta llegar a las fotos carné, que nos hablan de la expansión del Estado y sus requerimientos de documentos de identidad para innumerables y tediosos trámites, quien sabe tal vez por eso el aburrimiento de muchos de los rostros. Pero también nos habla de la democratización social, que no necesariamente avanza con la democratización política, y allí podemos sospechar las causas de la tragedia que vendría. Nos habla finalmente del anonimato de las ciudades modernas. Ya no están, o no se notan, los señores con nombres y apellidos decentes, conocidos, respetados, rimbombantes, sino los rostros anónimos (Degregori, en Mohana, 2001).

La descripción de Degregori destaca por su carencia de nostalgias. Muy diferentes son las descripciones de González Carré, Urrutia y Gutiérrez, autores de La ciudad de Huamanga. Espacio, historia y cultura (1995). Ellos expresan añoranza por la ciudad que cambió - aun cuando ex profeso dicen que no pretenden hacer de su libro uno de nostalgias-, combinada con un forzado optimismo. En términos arquitectónicos, manifiestan que de la Huamanga colonial quedan más recuerdos que patrimonio material, por tanto, plantean incorporar lo que de este queda en la «identidad colectiva». Posiblemente buscaban que los nuevos huamanguinos se identifiquen con ellos y los conserven.

Hoy que escribimos estas líneas, la tranquilidad y la paz de la antigua Huamanga colonial ya no existe más. Sus señoriales casonas, sus antiguos templos y conventos, sus barrios coloniales de artesanos y comerciantes son casi recuerdo de añorados años donde la ciudad ejercía una atracción irresistible de escritores, artistas, científicos y viajeros, que buscaban con especial 
sensibilidad un rincón de los Andes para vivir con dimensión humana, es decir «un pueblo pequeño de gesto antiguo». Pero este no es un libro de nostalgias sino de realidades que señalan que el nuevo rostro del Perú está allí, en gestación cotidiana. Lo importante es lograr la incorporación en la identidad colectiva del patrimonio cultural y sobre todo monumental (González, Gutiérrez y Urrutia, 1995, p. 153).

Uno de los autores del libro arriba indicado, Enrique González Carré, publicó años después Huamanga. Una breve historia (1998), con el objetivo de levantar su voz para expresar su «protesta» y «reclamo» por las malas condiciones de la ciudad. Describe sus riquezas y su menoscabo, que se pone de manifiesto fundamentalmente en la destrucción de su arquitectura colonial.

Ayacucho es una de las ciudades con mayor significación histórica, así como poseedora de una rica tradición arquitectónica y de un importante patrimonio cultural y monumental del Perú. Su deterioro —o destrucción aceleradaconstituye un delito de parte de sus agentes y de quienes justifican su acción en nombre de un progreso mal entendido y, desde todo punto de vista cuestionable [...] pero todo lo dicho acerca de las bondades del Ayacucho histórico no significa nada para quienes no detienen su destrucción. Los tiempos actuales recubren todo de cemento y reemplazan techos de tejas por calaminas. Las casonas se derrumban o son demolidas - ex profeso - para reemplazarlas por construcciones de ladrillo que imitan el dudoso gusto de cualquier barrio periférico de Lima.

Las iglesias y conventos no escapan a esto. Las torres de la catedral y su frontis han sido recubiertas de un empaste rosado sobre el cual se han dibujado ladrillos. Otras torres de otras iglesias han sido recubiertas de «material noble». Esta acción y gusto «modernizante» pretende cubrirlo todo de cemento y se caracteriza por un afán de derruir y destruir todo lo colonial. Sin embargo, las construcciones llamadas «modernas» se hacen muy pronto viejas, son vulgares copias de lo costeño y resultan estrechas e inadaptadas para las elementales formas de vida, en especial de la vida huamanguina, que suponía una casa con pequeña huerta y corral para las aves (González Carré, 1998, pp. 11-12).

Valga la larga descripción de González Carré para encontrar ciertas similitudes con las descripciones que sobre Ayacucho hicieron los viajeros limeños durante las primeras décadas del siglo XX. No solo comparten el clamor referido a que todo tiempo pasado fue mejor, sino que es posible encontrar miradas comunes sobre la ciudad, coincidencia en las escenas que les llaman la atención, y hasta críticas similares. 
Por ejemplo, Riva Agüero, durante su paso por Ayacucho en 1912, da cuenta de la incorporación de símbolos de modernización en la ciudad que se expresan en el cambio de las tejas por calaminas, lo cual lamenta amargamente: «Lástima es que, por baratura o necia moda, van reemplazando las tejas coloradas, tan hermosas y alegres, con la prosaica, gris y vilísima calamina, tan antipática» (Riva-Agüero, 1969, p. 146). En la misma línea, Aurelio Miró Quesada, en su libro Costa, Sierra y Montaña, publicado en 1938, critica la estética, el color y los nuevos materiales utilizados en la reconstrucción del recinto municipal, los que se alejan de lo que llama «el espíritu esencial de la arquitectura de Ayacucho». También se queja de que la «elegancia de las tejas» haya sido suplida «por una insufrible calamina» (Miró Quesada, 1974, p. 403). Alayza y Paz Soldán contrasta, en algunas de sus narraciones, las transformaciones ocurridas en esos largos dieciocho años que median entre su primer (1925) y segundo viaje (1943) a la ciudad; narra el caso del «ricacho de la urbe», que se definía como moderno, por lo cual derruyó todo vestigio de tradición de su casona y reconstruyó la fachada con «yeso» y «pintura alegre». Muestra indignación por las acciones contra la «dignidad y vetustez» producidas en Ayacucho y por «la epidemia demoledora» en cuyo nombre, dice, se ha cometido «toda clase de crímenes» (Alayza y Paz Soldán, 1974, pp. 339-340) ${ }^{10}$.

El tono narrativo de lamento de González Carré es, sin embargo, la reivindicación de la ciudad de un huamanguino por adscripción a esa tierra, por matrimonio y por el tiempo pasado en ella, pues él es por nacimiento trujillano. La memoria nostálgica de González Carré busca aprisionar a una ciudad que ya no está en el presente y que ya no regresará, pero en la que con seguridad le gustaría seguir viviendo, cuando menos, haciendo uso de una escenografía arquitectónica colonial simulada. Los años generan cambios inexorables, el devenir de los tiempos hace que lo nuevo se transforme en viejo y la nostalgia produce que lo viejo se convierta en lo deseado.

La arquitectura no es un arte que se relaciona solo con el espacio sino también con el tiempo; en tal sentido, puede contribuir a aplacar el miedo de su transcurrir (Harries, 2000, p. 214). En esa lógica, el objetivo de las construcciones «no es iluminar la realidad temporal con el fin de que podamos sentirnos más cómodos en ella, sino liberarnos de ella: abolir el tiempo dentro del tiempo, aunque sea por un tiempo» (Harries, citado por Harvey, 2004, p. 231). En el contexto de aceleración

10 Un análisis detallado de las descripciones de los viajeros limeños y las de los ayacuchanos sobre la ciudad de las primeras décadas del siglo XX se puede encontrar en el capítulo 1 de De la muy noble ciudad de San Juan de la Frontera de Huamanga a la arcadia decadente de Trinidad (2013). 
en que vivimos, la fijación del tiempo a través de la arquitectura para aferrarse al pasado es también una compensación contra la incertidumbre del futuro. En ese sentido, es posible entender la eficacia de los simulacros arquitectónicos, no solo pensando en los turistas sino también en los pobladores locales de Ayacucho, como medio para aplacar sus ansiedades.

Ellos están seguros de lo que Ayacucho fue en el pasado, pero no de lo que será en el futuro. Del pasado tienen la seguridad de que fue, como ya se mencionó, una de las ciudades más importantes y prósperas de la colonia. Ello podría explicar el porqué de mantener la arquitectura colonial como un blasón que los hace rememorar con orgullo esa época obliterando su contrapartida: que durante esa etapa colonial tenían una posición subordinada frente al imperio.

El olvido de la asociación de la arquitectura con el poder y su relación con la subjetividad de quienes la experimentan en su cotidianidad no solo se da en Ayacucho sino también en otros ex lugares coloniales, como por ejemplo Quito y Cuenca, estudiados por Radcliffe y Westwood (1999). Las autoras plantean que también ahí se busca conservar la arquitectura colonial para representar la «identidad ecuatoriana auténtica», dado que está asociada a memorias de cuando «la riqueza y la importancia de Quito y Cuenca eran mucho más grandes», pero olvidando «la manifiesta política española asociada a utilizar las ciudades para controlar las poblaciones conquistadas» (Al Sayyad, 1992, citado por Radcliffe y Westwood, 1999, p. 92). Ello tiene implicancias en las «representaciones oficiales contemporáneas» de ambas ciudades, en las que se muestran netamente coloniales: «Las representaciones oficiales contemporáneas retornan a una edad dorada de la arquitectura (e implícitamente, a una sociedad dorada)» (Radcliffe y Westwood, 1999).

A partir de ello es posible decir, para el caso de Ayacucho, que la arquitectura que se muestra en las representaciones turísticas, institucionales y oficiales tiene que estar mimetizada más con el entorno colonial, en el que la ciudad era la Morada del Alma, que con la arquitectura republicana. Es decir, debe representar una ciudad previa a las debacles poblacionales, las deformaciones estilísticas, los cambios sociales y el conflicto armado interno. El buscar ese contraste indica que no es casual que, llegado el milenio, se hayan rescatado archivos fotográficos compuestos por imágenes de un Ayacucho diferente del contemporáneo. Tales son los casos de El archivo digital de Baldomero Alejos ${ }^{11}$, la exposición fotográfica titulada Momentos (2007) — bajo la curaduría del ingeniero Juan Mendoza- y la página Recuperación de la ciudad de Huamanga en la red social Facebook.

11 Archivo digital de Baldomero Alejos https://www.archivoalejos.org (acceso: 9/1/2018). 
El archivo digital de Baldomero Alejos pone énfasis, en la presentación de su página web, en que las imágenes del fotógrafo muestran a un «Ayacucho en un clima de paz previo a los años oscuros de la violencia política $\rangle^{12}$. Una selección de las fotografías se publicó en el libro Baldomero Alejos, Ayacucho 1924-1956, el cual fue editado por la fotógrafa Mayu Mohana (2001). Este libro consta, además, de un dossier de entrevistas realizadas a varias personas retratadas, quienes dan cuenta a través de sus recuerdos y narraciones de cómo era la ciudad previa al conflicto. También se realizaron dos exposiciones fotográficas, una en Lima, titulada Baldomero Alejos, Ayacucho 1924-1976 ${ }^{13}$ y otra en Ayacucho, titulada Ayacucho: tiempos de $\mathrm{paz}^{14}$. El tenor fue el mismo: difundir visualmente el otro Ayacucho, con el fin de desempañarlo de la sangre y el terror. Una de las críticas que se hizo al libro de Mohana (2001) fue que las fotografías representaban a una élite. Ciertamente, el fotógrafo era un maestro del retoque y era requerido por las llamadas familias visibles para ser retratadas. Argumentando que esa era solo una parte de Ayacucho - y por tanto no representativa - en el año 2007 Juan Mendoza reunió un total de 147 fotografías de diversa procedencia y formato, que datan de los años 1900 hasta principios de la década de 1970, y organizó la exposición fotográfica Momentos en Ayacucho. Tal como indica el título de la exposición, las fotografías fueron organizadas en seis momentos que daban cuenta, según dice Mendoza, «de los grandes procesos, los de largo plazo, aquellos que hasta ahora nos acompañan y explican nuestro presente». Al igual que en el caso anterior, el objetivo fue difundir visualmente la existencia de un Ayacucho previo al conflicto. El argumento de Mendoza era hacer que «el ayacuchano de hoy [2007] recupere su identidad» $y$, podríamos añadir, la memoria:

Dos generaciones de ayacuchanos han crecido en medio de un conflicto y su referencia de pasado es el más reciente, y lo mismo pasa con las generaciones anteriores a la guerra, han borrado lo que pasó antes y se han quedado con el recuerdo de los ochentas. Es lamentable decirlo, pero los ayacuchanos no tienen memoria de sus procesos históricos, y por ello es necesario el esfuerzo por retomar las tradiciones, instituciones y memoria, respecto a los grandes mitos ayacuchanos desde la independencia del Perú (Juan Mendoza, entrevista en el diario La República, 28 de mayo de 2007).

12 Presentación del archivo digital de Baldomero Alejos que actualmente se encuentra descontinuada http://archivoalejos.org/site_es/content02.html_(acceso: 14/7/2013).

13 Baldomero Alejos 1924-1976. Instituto Peruano Norteamericano (ICPNA), 2001.

14 Ayacucho tiempos de paz. Centro Cultural San Cristóbal de Huamanga, Ayacucho. Marzo-abril de 2005. 
En la línea de recuperar la memoria del pasado previo a la guerra, apelando a los recursos visuales para hacer ver lo que quedó invisibilizado, Jaime Pacheco, quien se autodefine como huamanguino, creó junto con un grupo de amigos en el año 2013 la página Recuperación de Huamanga en la red social Facebook ${ }^{15}$. Pacheco ${ }^{16}$, quien es realizador audiovisual, dice que todo empezó como jugando. En su intención de hacer una película con un tema de época, se puso a buscar locaciones y descubrió que la ciudad estaba deteriorada: «Ya no había nada de lo que yo mismo había vivido de cuando niño, de cuando joven». Esa fue la razón que lo motivó a abrir una página «para que la gente pudiera conocer» como fue la ciudad de antes. Primero la página se llamó Recuperación de Huamanga Señorial, la que se empezó a llenar de fotos antiguas de propiedad de los integrantes del grupo. Una mirada a la cronología del posteo de fotografías es reveladora del cambio en la temática de la página. Inicialmente se trataba de fotos en blanco y negro y en sepia, y algunas en color, sobre arquitectura de la ciudad y a las familias que la poblaban. Paulatinamente, se empezaron a compartir fotografías que se referían a los problemas que afectaban la actualidad de la ciudad, centrándose en la destrucción de la arquitectura, civil y religiosa y la proliferación de las construcciones ilegales.

La página pasó de ser un espacio inicial de construcción de memoria colectiva y sentido de pertenencia - una forma no solo «de vincular a las personas con el lugar» sino también de «evocar la noción de lealtad al lugar» (Lovell, 1998, p. 1) - a ser un espacio en el cual los participantes asumieron un rol proactivo utilizando el recurso virtual para propiciar un debate y reclamo a las autoridades sobre el descuido de «su» ciudad. Uso las comillas porque el modelo de ciudad que imaginan tiene características determinadas en términos del poblador, sus actividades y sus gustos, tal como se puede interpretar por lo expuesto en la información de la página:

Muchas de las viejas casonas se van derruyendo y en su lugar se construyen cajones de cemento y sin nada de estética que guarde arquitectónica [sic] con las viejas calles. Las viejas casonas por las noches, son bañadas con mangueras por los nuevos propietarios para debilitarlas y derruirlas con justificación de que ya están viejas y que caerán más rápido y es así que hoy en día vemos en nuestras calles, una nueva construcción de material noble (CEMENTO),

\footnotetext{
15 Creada el 17 de febrero de 2013, a enero de 2018 cuenta con un total de 7564 seguidores. URL: https://www.facebook.com/pg/RecuperacionDeHuamangaSenorial/about/?ref=page_internal (acceso: 10 de enero de 2018).

16 Entrevista, 6 de enero de 2018.
} 
con tan mal gusto, que hace un mal contraste con una calle antigua y colonial, esto a su vez, no importa a nadie pues la oportunidad es negocio, por sobre todo en el viejo cercado de la vieja Huamanga.

La información de la página expresa indignación por el deterioro de la ciudad y exuda nostalgia por la ciudad señorial que se ha ido: «Esta Huamanga señorial que hoy en día, se ha ido perdiendo en el olvido y dejadez de sus autoridades, se ha ido realmente perdiendo a lo largo del tiempo y sin más miramiento que solo la desidia de no conservarla». Para los huamanguinos administradores de la página, la ciudad está enajenada no solo porque los nuevos huamanguinos que no tienen sentido de pertenencia local la han poblado, sino también porque sus autoridades, al no ser originarias de Ayacucho, no reconocen su historia ni sus tradiciones. Por ejemplo, señalan que el alcalde provincial de Huamanga de la gestión 2015-2018, Salomón Hugo Aedo Mendoza, ostentaba tal cargo siendo natural de Chincha.

¿Qué significa mirar nostálgicamente al pasado a través de la fotografía? La nostalgia puede ser entendida como un síntoma que expresa la «pérdida de confianza en el presente» (Lowenthal, 1998, p. 41). Cuando el presente «por sí solo no se adecua a nuestros deseos», lo reducimos para engrandecer el pasado. El desencanto en el presente puede conducir a desear recuperar el ayer de diversas formas que van desde «una devoción por las reliquias, el atesoramiento de las antigüedades y recuerdos, la tendencia a apreciar lo que es viejo simplemente por ser viejo y el rechazo del cambio» (Lowenthal, 1998, p. 69). Ello explicaría la notoriedad que han logrado la recuperación del archivo fotográfico de Baldomero Alejos por Mohana, así como las fotografías recopiladas por Juan Mendoza y las albergadas en la página web Recuperación de Huamanga, fotografías de la arquitectura y paisajes de la ciudad que muchos quizá no conocieron, pero que hubieran deseado conocer. A partir de ello es posible entender que se culpabilice a la nostalgia «de alienar a la gente respecto del presente» (Lowenthal, 1998, p. 41). Sin embargo, la nostalgia también tiene ciertas «virtudes compensadoras»: según Lowenthal, «el apego a lugares familiares puede amortiguar el cataclismo social, el apego a las caras conocidas puede ser necesario para tolerar la vida en sociedad». Podría entonces servir, en Ayacucho, para mitigar el desastre social y físico sentido en la ciudad a causa del conflicto armado interno que produjo la desconfianza hacia el otro y la depredación de lo humano. La nostalgia, dice el autor, también podría servir para «reafirmar las identidades magulladas por el desorden reciente», por ejemplo, cuando «las convicciones fundamentales establecidas acerca del hombre, la mujer, las costumbres, los modales, las leyes, 
la sociedad y Dios eran desafiadas, interrumpidas y agitadas» (Lowenthal, 1998, p. 41). Entonces, la utilización nostálgica de la fotografía, como evocador de memoria de un pasado más glorioso, podría significar un deseo de remediar simbólicamente las huellas aún presentes del dolor dejado por la violencia.

\section{CODA: MEMORIA Y VISUALIDAD}

El término memoria, según se ha podido apreciar, es polisémico, y dependiendo de quién sea el gestor, sus agendas e intereses, se fijará en el tiempo y el espacio invocado. El uso de la tecnología de la imagen como evocador de memoria es un recurso utilizado y utilizable para construir identificaciones locales y sentimientos de pertenencia, pero también de exclusiones sociales. No obstante, las nuevas formas de distinción, no basadas en un supuesto linaje sino en el éxito económico, la competitividad y el consumo son los nuevos referentes de la ciudad. Siendo la arquitectura expresión de poder, las estéticas híbridas, el collage de materiales con las que se construyen y los diseños eclécticos que se utilizan en el Ayacucho contemporáneo pueden ser interpretados como expresión de resistencia contra el modelo hegemónico colonial, como subversión simbólica de las normas con las que se busca encasillar a la ciudad como simulacro colonial y como rechazo a la fijación de una identidad única. Ayacucho está en un proceso de búsqueda. Aún no es, pero está en camino a ser. Y, para ser, quizá no cabe mirar nostálgicamente al pasado sino construir el futuro desde su presente.

\section{REFERENCIAS}

Alayza y Paz Soldán, Luis (1974). Mi país. En Consejo Nacional de la Universidad Peruana, Huamanga, una larga historia (pp. 331-354). Lima: CONUP.

Bachelard, Gastón (1958). El aire y los sueños. Ensayo sobre la imaginación del movimiento. México D.F.: Fondo de Cultura.

Baudrillard, Jean (1978). Cultura y simulacro. Barcelona: Kairos.

Benjamin, Walter (2011). La obra de arte en la era de su reproducción técnica. Buenos Aires: El Cuenco de Plata.

Berger, John, Sven Blomberg, Chris Fox y Michael Dibb, Richard Hollis (1974). Modos de ver. Barcelona: GG.

Castro-Gómez, Santiago (2000). Ciencias sociales, violencia epistémica y el problema de la «invención del otro». En Edgardo Lander (comp.), La colonialidad del 
saber: eurocentrismo y ciencias sociales. Perspectivas latinoamericanas (pp. 88-98). Buenos Aires: Clacso. Recuperado el 13/07/2013 de http://bibliotecavirtual.clacso.org.ar/ar/libros/lander/castro.rtf

Cavero, Ranulfo (2005). ¡Ayacucho!: ¿Rincón de los Muertos o Morada del Alma? Ayacucho: Universidad Nacional de San Cristóbal de Huamanga.

Fontcuberta, Joan (1997). El beso de Judas: fotografía y verdad. Barcelona: GG.

González Carré, Enrique (1998). Huamanga, una breve historia. Ayacucho: Universidad Nacional de San Cristóbal de Huamanga.

González Carré, Enrique, Yuri Gutiérrez y Jaime Urrutia (1995). La ciudad de Huamanga: espacio, historia y cultura. Lima: Universidad Nacional de San Cristóbal de Huamanga, Concejo Provincial de Huamanga, Centro Peruano de Estudios Sociales.

Gonzalez Stephan, Beatriz (1994). Escritura y modernización: la domesticación de la barbarie. Revista Iberoamericana, LX(166-167), 110-124. Recuperado el 9/1/2018 de https://revista-iberoamericana.pitt.edu/ojs/index.php/Iberoamericana/article/view/6494/6670

Guarné Cabello, Blai (2004). Imágenes de la diferencia. Alteridad, discurso y representación. En Elisenda Ardevol y Nora Muntañola (coords.), Representación y cultura audiovisual en la sociedad contemporánea (pp. 47-127). Barcelona: UAO.

Harries, Karsten (2000). The Ethical Function of Architecture. Cambridge, MA: MIT Press.

Harvey, David (2004). La condición de la postmodernidad: investigación sobre los orígenes del cambio cultural. Buenos Aires: Amorrortu.

Lins Correa, Elyane (2007). Urbanizações temáticas: arquiteturas do desejo. Cadernos PPG-AU/UFBA, 6, 49-59. Recuperado el 9/1/2018 de https://portalseer.ufba.br/ index.php/ppgau/article/view/2635/1857

Lovell, Nadia (1998). Locality and Belonging. Londres: Routledge.

Lowenthal, David (1998). El pasado es un país extraño. Madrid: Akal.

Miró Quesada, Aurelio (1974). Sierra y montaña. En Consejo Nacional de la Universidad Peruana, Huamanga, una larga historia (pp. 397-429). Lima: CONUP.

Mohana, Mayu (ed.) (2001). Baldomero Alejos: Ayacucho 1924-1976. Lima: ICPNA.

Radcliffe, Sarah y Sallie Westwood (1999). Rehaciendo la nación. Lugar, identidad y política en América Latina. Quito: Abya-Yala.

Rifkin, Jeremy (2000). La era del acceso, la revolución de la nueva economía. Barcelona: Paidós. 
Riva Agüero, José Luis (1969). Paisajes peruanos. Lima: Pontificia Universidad Católica del Perú.

Riviere, Margarita (22 de octubre, 2000). Estamos en un capitalismo cultural. Entrevista a Jeremy Rifkin. El País,

Trinidad, Rocío (2006). Ayacucho, ciudad y arquitectura. Entre la fantasía colonial y la pesadilla híbrida. Urbes, 3, 9-28. Lima, enero-diciembre de 2006.

Trinidad, Rocío (2013). (Re)presentando Ayacucho: debates en torno al cambio, el turismo y la imagen arquitectónica en tres momentos históricos. Tesis presentada para optar el grado de doctora en Antropología. Pontificia Universidad Católica del Perú.

Urry, John (2004). La mirada del turista. Lima: Universidad de San Martín de Porres.

Vich, Víctor (2007). Magical Mystical: el Royal Tour de Alejandro Toledo. En Santiago López Maguiña, Gonzalo Portocarrero, Rocío Silva Santisteban, Juan Carlos Ubilluz y Víctor Vich (eds.), Industrias culturales (pp. 313-325). Lima: Red para el Desarrollo de las Ciencias Sociales en el Perú. 